Case Report

\title{
Peutz-Jeghers Syndrome: Need for Genetic Charting
}

\author{
Poonam Rani', Khushboo Dewann ${ }^{2}$, Kusum Gupta $^{3}$, AK Mandal $^{4}$
}

${ }^{1}$ Tutor, ${ }^{2}$ Assistant Professor, ${ }^{3,4}$ Professor, Department of Pathology, Dr. Baba Saheb Ambedkar Medical College and Hospital, Delhi, Rohini, Delhi, India.

DOI: https://doi.org/10.24321/2454.8642.201912

\section{I $\quad \mathbf{N} \quad \mathbf{F} \quad \mathbf{O}$}

\author{
Corresponding Author: \\ Poonam Rani, Department of Pathology, Dr. Baba \\ Saheb Ambedkar Medical College and Hospital, \\ Delhi, Rohini, Delhi, India. \\ E-mail Id: \\ poonambsamch@gmail.com \\ Orcid Id: \\ https://orcid.org/0000-0003-3725-6934 \\ How to cite this article: \\ Rani P, Dewan K, Gupta K et al. Peutz - Jeghers \\ Syndrome: Need for Genetic Charting. Rec Adv \\ Path Lab Med 2019; 5(2): 31-35. \\ Date of Submission: 2019-07-13 \\ Date of Acceptance: 2019-08-16
}

\section{$\begin{array}{llllllllllll}\mathbf{A} & \mathbf{B} & \mathbf{S} & \mathbf{T} & \mathbf{R} & \mathbf{A} & \mathbf{C} & \mathbf{T}\end{array}$}

Peutz-Jeghers Syndrome (PJS) is an autosomal dominant inherited disorder with characteristic melanin pigmentation and hamartomatous polyps in the gastrointestinal tract. This syndrome is associated with increased risk of gastrointestinal, pancreatic, lung, breast, ovarian, uterine and testicular malignancies, hence timely diagnosis and regular follow up are necessary. Here we are presenting a case of a 15-year-old female who presented with complaints of abdominal pain, vomiting, and loose stools. The CT scan showed a large jejunoileal intussusception. Intraoperatively the intussusception was reduced and resected. The jejunum was filled with multiple polyps. A microscopic examination from the polyps showed a complex glandular architecture with the presence of smooth muscle bundles intermixed with lamina propria, consistent with hamartomatous polyps. The patient was re-examined to find possible evidence of PJS. She had mucocutaneous pigmentation on lips and medial aspects of eyes. Pedigree analysis of the family revealed that her siblings, father, grandmother and great grandfather also had brown macules on their lips. She was on the ventilator and expired 3 days post-surgery due to cardiac arrest and anastomotic leakage. The family was further advised to follow up and screening to avoid future complications and malignant transformation.

Keywords: Peutz-Jeghers Syndrome, Intussusception, Pedigree Analysis, Hamartomatous Polyps

\section{Introduction}

Peutz-Jeghers Syndrome (PJS) is an inherited disorder with characteristic gastrointestinal hamartomatous polyps and distinctive type of melanin pigmentation on the mucosa of the oral cavity, lips, hands and feet. The mode of inheritance is autosomal dominant. Incidence of this inherited condition varies from 1 in 8,300 to 1 in 280,000 live births. ${ }^{1}$ It was first described in 1921 by a Dutch doctor named Jan Peutz who discerned a connection between gastrointestinal polyps and hyperpigmentation in members of a family. ${ }^{2}$ In 1949 ,
Harold Jeghers, an American doctor made a brief report of 10 cases with distinctive mucocutaneous pigmentation and generalized intestinal polyposis and suggested this syndrome to be of diagnostic significance. ${ }^{3}$ These hamartomatous polyps usually result in various complications such as intussusception, bowel obstruction and bleeding which sometimes can be fatal. ${ }^{4}$ This syndrome is associated with increased risk of gastrointestinal, pancreatic, lung, breast, ovarian, uterine and testicular malignancies. ${ }^{5}$

The diagnosis of PJS if made early, can circumvent future 
complications such as acute intestinal obstruction, bleeding, and intussusception and detect malignancies at an early stage if it develop.

\section{Case Report}

A 15-year-old female was presented to medical emergency with complaints of pain abdomen and vomiting and loose stools for 5 days. Five years ago she had a previous history of cholecystectomy. The record was not available. The patient did not attain menarche. On examination, the patient was afebrile with BP $-100 / 70 \mathrm{~mm} \mathrm{Hg}$ and a respiratory rate of $80 / \mathrm{min}$. The lower abdomen was tender on examination. There was no guarding, rigidity or abdominal distension. A lump of approximate size $5 \times 5 \mathrm{~cm}$ was palpable in the lower left abdomen.

\section{USG Abdomen}

The infraumbilical and paraumbilical area region showed a large round to cylindrical structure with a concentric ringlike appearance with invaginated mesentery. The possibility of intussusception was given.

\section{CT Scan of the Whole Abdomen}

A large jejunoileal intussusception is seen with engorged mesenteric vessels and enlarged mesenteric lymph nodes causing dilatation of proximal jejunal loops and duodenum with obstructive changes (Figure1). Bilateral mild pleural effusion with adjacent atelectatic changes were observed. Mild ascites noted. Fatty hepatomegaly also was seen.

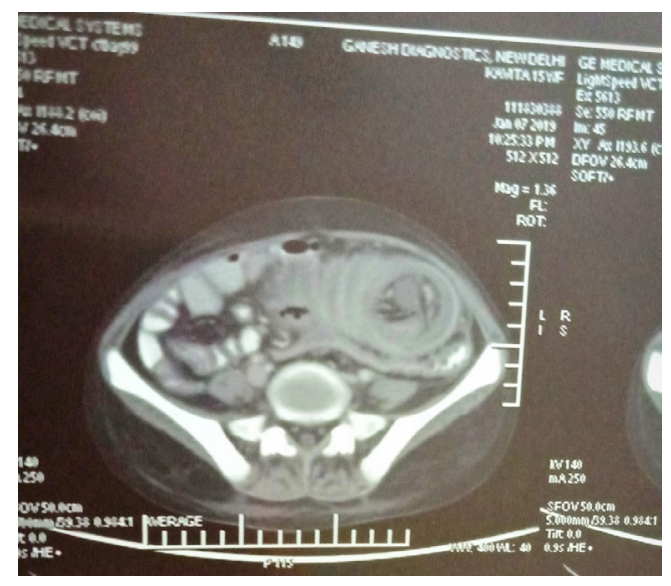

Figure I.CT scan abdomen shows characteristic

'Target sign' (arrow) suggestive of intussusseption Intraoperative Findings

There was a jejunoileal intussusception located $1 / 2$ feet from the duodenojejunal junction. Approximately 2.5 feet jejunoileal segment was resected. The jejunum was filled with multiple polyps. Multiple perforations were seen in the jejunum (Figure 2). All the polyps were not removed. Intussusception was reduced intraoperatively and then the specimen was sent for histopathological examination.
Postoperatively the patient went into arrhythmia and hypokalemia. (potassium ions-2.1) and the patient was shifted to ICU and kept on mechanical ventilation. There was midline discharge. The patient suddenly went into cardiac arrest and could not be revived.

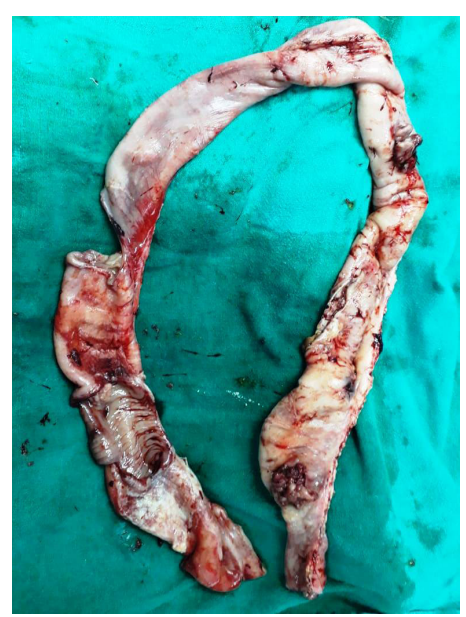

Figure 2.Intra operative findings: The jejunoileal intestinal segment showing multiple perforations (white arrows) and polyps (black arrows)

\section{Gross Findings}

We received an already reduced jejunoileal segment of intestine measuring $50 \mathrm{~cm}$ long. Externally multiple perforations were seen which were exudate covered. On the cut section, multiple polyps were seen ranging in size from $1 \mathrm{~cm}$ to $4 \mathrm{~cm}$ in diameter (Figure 3). One of the polyps was $0.5 \mathrm{~cm}$ away from the smaller resected end. Most of the polyps had a broad base. (peduncle). Few polyps were present at the site of the perforation. Multiple sections were taken from polyps.

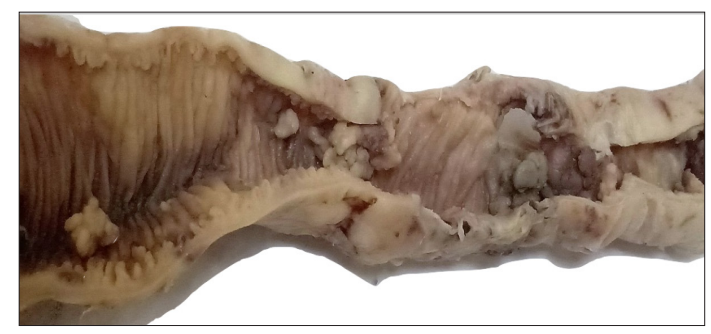

Figure 3.Gross examination: The intestinal segment shows multiple polyps of varying sizes and congestion of the mucosa

\section{Microscopic Examination}

Sections from polyps showed complex glandular architecture with the presence of smooth muscle bundles intermixed with lamina propria, consistent with Peutz Zeghers polyposis (Figure 4). Sections from the perforation site showed ulceration of mucosa with submucosal edema and congestion with marked serositis. 


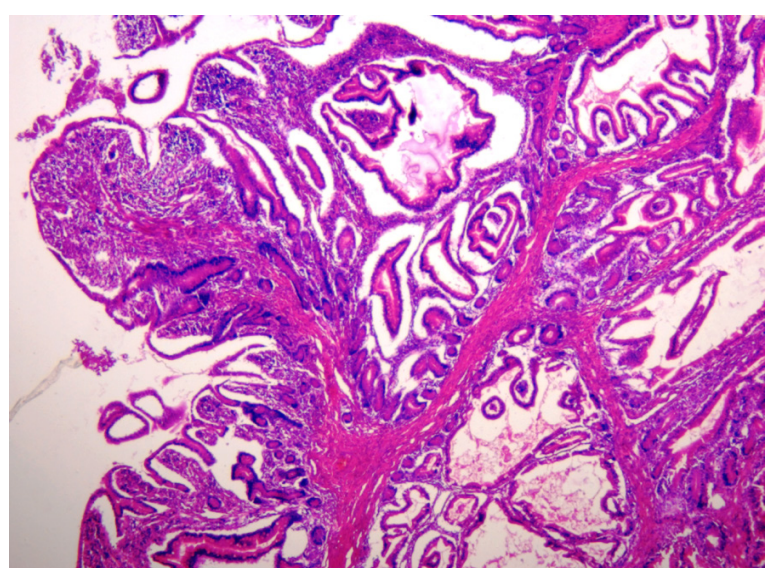

Figure 4.Microscopic examination: Hamartomatous polyps with complex glandular architecture and arborizing pattern of smooth muscle bundles. H\&E, I00X

\section{Patient Examination}

The patient was re-examined to find possible evidence of PJS. Consent was taken from the patient's father. She had mucocutaneous pigmentation on lips (Figure 5). On examination, no lump was identified in bilateral breasts. The ultrasound did not yield any abnormality in the reproductive system. During the post-operative phase, the patient developed complications due to anastomotic leakage and cardiac arrest. She was on the ventilator and expired 3 days post-surgery.

In view of multiple Peutz-Jeghers polyps, mucocutaneous pigmentation, and family history, the patient was diagnosed as Peutz-Jeghers syndrome.

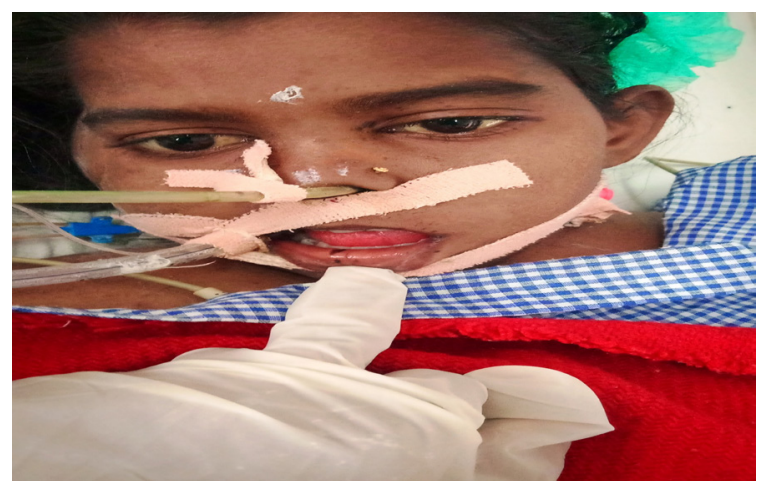

Figure 5.The patient showing brown macules on lower lip indicated by white arrow

\section{Pedigree Analysis}

Her siblings, father, grandmother and great grandfather also had brown macules on lips (Figure 6). Her maternal side is completely normal. The patient's brother got operated a few months back for an acute abdomen and a part of intestine was removed, no records were available regarding the diagnosis.
Her aunt died of lumps in the intestine as per the details are given by patients' relative but records were not available. Thus the pedigree chart shows that the Peutz Jegher gene is autosomal dominant (Figure 7). The family was further advised a follow up and screening.

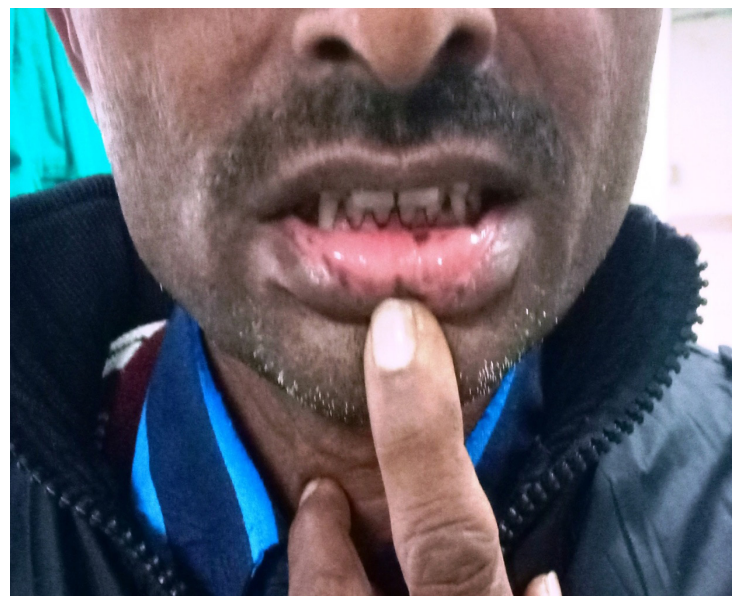

Figure 6.Patient's father showing brown macules on lip (arrow)

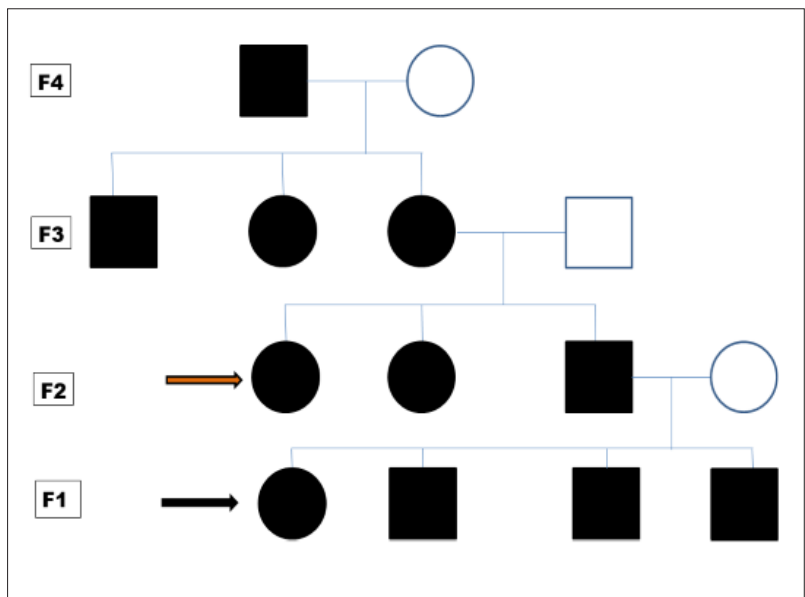

Figure 7.Pedigree analysis of four generations of PJS was done. The index case is shown by black arrow.

Black symbols denote individuals with mucocutaneous pigmentations. Circles and squares indicate females and males, respectively. Patients' father, aunts, grand-mother, great grandfather and all the siblings had brown macules on lips. One of the brothers got operated a few months back for acute abdomen and a part of the intestine was removed and there were no records available regarding the diagnosis. Her aunt (brown arrow) died of lumps in the intestine as per the details given by patients' father but the records were not available. The patients' maternal side was completely normal. FI, F2, F3 and F4 represent families, FI being family of reported case.

Pedigree analysis shows autosomal dominant inheritance pattern of PJS gene 


\section{Discussion}

PJS is caused by a germline mutation in the STK11 tumor suppressor gene in $80-94 \%$ of the cases. 6 However in the year 2014, two novel mutations OR4C45 and ZAN were detected in a study on Chinese families.7 One of the WHO criteria 8 should be fulfilled for the diagnosis of PJS:

- $\quad \geq 3$ hamartomatous polyps

- Hamartomatous polyps and a family history of PJS

- Hamartomatous polyps and mucocutaneous pigmentation

- Mucocutaneous pigmentation and a family history of PJS

Approximately $95 \%$ of cases of PJS reveal characteristic mucocutaneous brown macules which may be the first sign and usually appear in the first decade of life and may however may be seen at birth also. ${ }^{5}$ The symptoms of PJS are mainly due to gastrointestinal polyps and initial symptoms usually start appearing by the age of 10 years with a peak at the age of $20-25$ years. ${ }^{9}$ Zhang $Y$ et al in 2017 correlated the genotype and phenotype of PJS in three families and suggested that oral pigmented lesions appear before gastrointestinal symptoms and their severity reflects the severity of GI phenotype. They proposed that the severity of oral pigmentation may be used as a diagnostic and prognostic marker of PJS. ${ }^{10}$ The risk of malignancies increases with age. Hence timely investigations in patients with mucocutaneous pigmentations can avoid complications due to polyps such as GI bleeding, intussusception and bowel obstruction.

As per ACG clinical guidelines for PJS, cancer screening is dependent upon gender. For men with PJS, testicular examination along with ultrasonography should be done annually. In women with PJS, monthly breast self-assessment and annual clinical breast examination should be performed. Starting at the age of 20 years, mammography should be done every 2-3 years then on a yearly basis at 40 years. By the age of 25 years, annual gynecological examination including ultrasonography, Pap smear and uterine biopsy is advised. ${ }^{11,12}$

Van Lier MG et al recommended surveillance protocols for PJS in 2010. Its two objectives were to detect malignancy at an early stage and to avoid complications due to intestinal polyps. ${ }^{11}$ Hence, surveillance guidelines include colonoscopy and upper $\mathrm{Gl}$ endoscopy starting at the age of 8 years. If polyps are detected, they can be managed by snaring the polyps or short length enterotomy of the profoundly involved intestinal segment and screening again every $2-3$ years. If no polyps are detected at the age of 8 years then endoscopy should be performed at the age of 18 years and then every 2 to 3 years thereafter. Patients with PJS need screening for pancreatic carcinoma as well which should start by 30 years of age and then after every $2-3$ years. ${ }^{11,12}$

Pedigree analysis of family members gives a clue of genetic transmission in such cases. Hence, regular follow up of family members and investigations result in early diagnosis and management of malignancies if occur.

\section{Conclusion}

We suggest that a mere diagnosis of Peutz Jeghers polyp is not enough and a pedigree chart/ genetic profiling must be made and all the patients and family members should be followed up for future complications and malignant transformation.

\section{Acknowledgment}

We would like to thank all the authors \& all staff members of the Department of Pathology, Dr. BSAMCH, Rohini, Delhi for their support \& encouragement in preparing this report. The authors declare that there is no conflict of interest.

\section{Conflict of Interest: None \\ References}

1. Lindor NM, McMaster ML, Lindor CJ et al. Concise Handbook of Familial Cancer Susceptibility Syndromes - second edition. J Natl Cancer Inst Monogr 2008; 38: 1-93.

2. Peutz JL. About a Very Peculiar, Combined Familial Pollyposis of the Intestinal Tract with that of the Nasal Throat and Accompanied by Peculiar Pigmentations of the Skin and Mucous Membranes. Ned Maandschr v Gen 1921; 10: 134.

3. Jeghers H, Mc KV, Katz KH. Generalized Intestinal Polyposis and Melanin Spots of the Oral Mucosa, Lips and Digits; a Syndrome of Diagnostic Significance. $N$ Engl J Med 1949; 241(26): 1031-1036.

4. Wang $\mathrm{H}$, Luo $\mathrm{T}$, Liu WQ et al. Clinical Presentations and Surgical Approach of Acute Intussusception Caused by Peutz-Jeghers Syndrome in Adults. J Gastrointest Surg 2011; 15: 2218-2225.

5. Kopacova M, Tacheci I, Rejchrt S et al. Peutz-Jeghers Syndrome: Diagnostic and Therapeutic Approach. World J Gastroenterol 2009; 15(5): 397-408.

6. Beggs AD, Latchford AR, Vasen HF et al. Peutz-Jeghers Syndrome: A Systematic Review and Recommendations for Management. Gut 2010; 59(7): 975-986.

7. Wang $\mathrm{HH}, \mathrm{Xie} N \mathrm{~N}$, Li QY et al. Exome Sequencing Revealed Novel Germline Mutations in Chinese PeutzJeghers Syndrome Patients. Dig Dis Sci 2014; 59(1): 64-71.

8. Aaltonen LA, Jarvin H, Gruber SB et al. Peutz-Jeghers syndrome. In: Hamilton SR, Aaltonen LA, eds. Tumors of the Digestive System. Lyon, France: IACR; 2000; 74-6.

9. Dong K, Li B. Peutz-Jeghers syndrome: Case Reports and Update on Diagnosis and Treatment. Chin J Dig 
Dis 2004; 5: 160-164.

10. Zhang $Y, K e ~ Y$, Zheng $X$ et al. Correlation Between Genotype and Phenotype in Three Families with PeutzJeghers Syndrome. Exp Ther Med 2017; 13(2): 507-514.

11. Van Lier MG, Wagner A, Mathus-Vliegen EM et al. High Cancer Risk in Peutz-Jeghers Syndrome: a Systematic Review and Surveillance Recommendations. Am J Gastroenterol 2010; 105(6): 1258-1264.

12. Syngal S, Brand RE, Church JM et al. ACG Clinical Guideline: Genetic Testing and Management of Hereditary Gastrointestinal Cancer Syndromes. Am J Gastroenterol 2015; 110(2): 223-262. 